\title{
A study on the effects of human resources strategies on the organizational performance: Evidence from Pharmaceutical industry
}

\author{
Mohammadreza Fadavi ${ }^{\mathrm{a}}$ and Ali Baqi ${ }^{\mathrm{b}^{*}}$
}

${ }^{a}$ Department of Management and Accounting, Naraq Branch, Islamic Azad University, Naraq, Iran ${ }^{b}$ Department of Management and Accounting, Kashan Branch, Islamic Azad University, Kashan, Iran

\section{H R O N I C L E}

Article history:

Received January 20, 2014

Accepted 5 July 2014

Available online

August 252014

Stock liquidity

Strategy

Human resources management

Organizational performance

Barij Essence Pharmaceuticals

\section{A B S T R A C T}

In order to improve the organizational performance, strategies in the human resources are among the elements taken into consideration. On this basis, the present research is aimed at studying the role of human resources strategies in the organizational performance of Barij Essence Kashan Pharmaceutical Company. In terms of goal, the present research is descriptivecorrelative and in terms of data collection, the survey method has been used. The main means of research data collection has been questionnaires and the validity and consistency tests have been carried out on the questionnaires. The statistical population is consisted of managers, directors, and experts of the Barij Essence Kashan Pharmaceutical Company during the winter of 2013-2014. Simple random sampling method has been used in the research and the number of people in the statistical population is 48 . In research data collection, both library and field (questionnaire) methods have been used. The Pearson correlation coefficient and the multivariate regression have been employed in analysis of the data. By verifying the examined hypothesis, the findings of the research reveal that the human resources strategies generally influence on the organizational performance in five groups of absorption and employment strategy, human resources development strategy, performance management strategy, service compensation strategy, and employees' relations strategy.

(C) 2014 Growing Science Ltd. All rights reserved.

\section{Introduction}

The performance of an organization and its personnel depends on different factors such as employee skills, organizational education, and innovation in that organization. These factors are associated with one another and directly or indirectly influence on the performance of an organization (Javanmard \& Sakhaei, 2011). Organizational performance is one of the most important constructs debated in management studies, and indubitably is amongst the most important measurement of success in commercial companies (Allameh \& Moghadami, 2010). Today, in the competitive atmosphere, many businesses try to prosper through an organizational performance achieved by creating a sustainable competitive advantage and adapt to the emerging changes. In present condition,

*Corresponding author

E-mail addresses: baqi1341@gmail.com (A. Baqi) 
competitive supremacy, value making, and guaranteeing long-term growth, increasingly depend on the human capital role of the organization, which means the collection of knowledge, attitude, conduct, capabilities and experience of the personnel (Allen \& Wright, 2006). Therefore, it can be said that human force could be considered as the most important competitive advantage for any firm and managers should know how to deal with this strategic factor and learn how to use this competitive advantage, more efficiently. The concept of human resources management was introduced in the mid 80's with the goal of providing ways to manage employee and to help improve the performance of organizations (Samei, 2009). Human resources management includes managing the most valuable assets of any company, which include the employees who work there and individually or together help the company reach its objectives. To reach this goal, one of the fundamental methods is to enter the strategic management into the human resources area and to create or to select suitable strategies for the work force occupied at the organization (Akhavan \& Pezashkan, 2012).

Strategic management of the human resources facilitates coordination among various activates of the organization, creating opportunities, and preventing possible threats (Abtahi \& Mousavi, 2010). Strategic operations of human resources is the primary tool employed by the organization for forming and influencing skills, tendencies, and the conducts of the individuals performing their occupational duties and as the result reaching for the goals of the organization and innovation (Sadeghi \& Mohtashami, 2012). Strategic management of human resources is general and comprehensive for managing the personnel's affairs and coordinating the human resources strategies with the commercial strategies of the company.

Strategic management of human resources is associated with the long-term issues related to the internal and the external environment of the organization and its outcome is policies for the fields of human resources (Chadwick, 2005). On one hand, the continued livelihood of every organization depends on its dynamic interaction with its internal and external environment. This interaction causes an incoming flow of information and latest technical and scientific findings of humans, which could lead to changes in the operation and the behavior of the organization. In addition, in this interaction, the organization must obtain its required resources and comply with the actual demands of its environment (Javanmard \& Sakhaei, 2011; Obzeri et al., 2009 ).

Selecting the suitable strategy in organizations is an influential element in the organizations' performance (Mazloumi et al., 2012). Measuring the effect of human resources strategies on the performance of the organization has occupied those involved with human resources. They are faced with the challenge of "how to measure this effect? Which is the best way to combine the role of human resources with measurement of business performance?" (Atafaret al., 2011). In addition, creating a true understanding of the relationship between the strategies adopted by organization and the organization performance can lead to a precise knowledge for the managers to aid them in their decision making (Mazloumi et al., 2012).

This paper performs a survey on measuring the effect of the human resources strategies on the organizational performance of the Barij Essence Pharmaceutical Company. In order to carry out the statistical examination and defining the level and type of relationship between the independent and dependent variants suited and similar with the aims of the research, the questions posed by the study are as follows:

The main question:

Do human resources strategies have an effect on the organizational performance? 
Secondary questions:

1. Does absorption and employment strategy influences on organizational performance?

2. Does human resources development strategy influence on organizational performance?

3. Does performance management strategy influence on organizational performance?

4. Does service compensation strategy influence on organizational performance?

5. Does employees' relations strategy service compensation influence on organizational performance?

Fig. 1 demonstrates the summary of the proposed study.

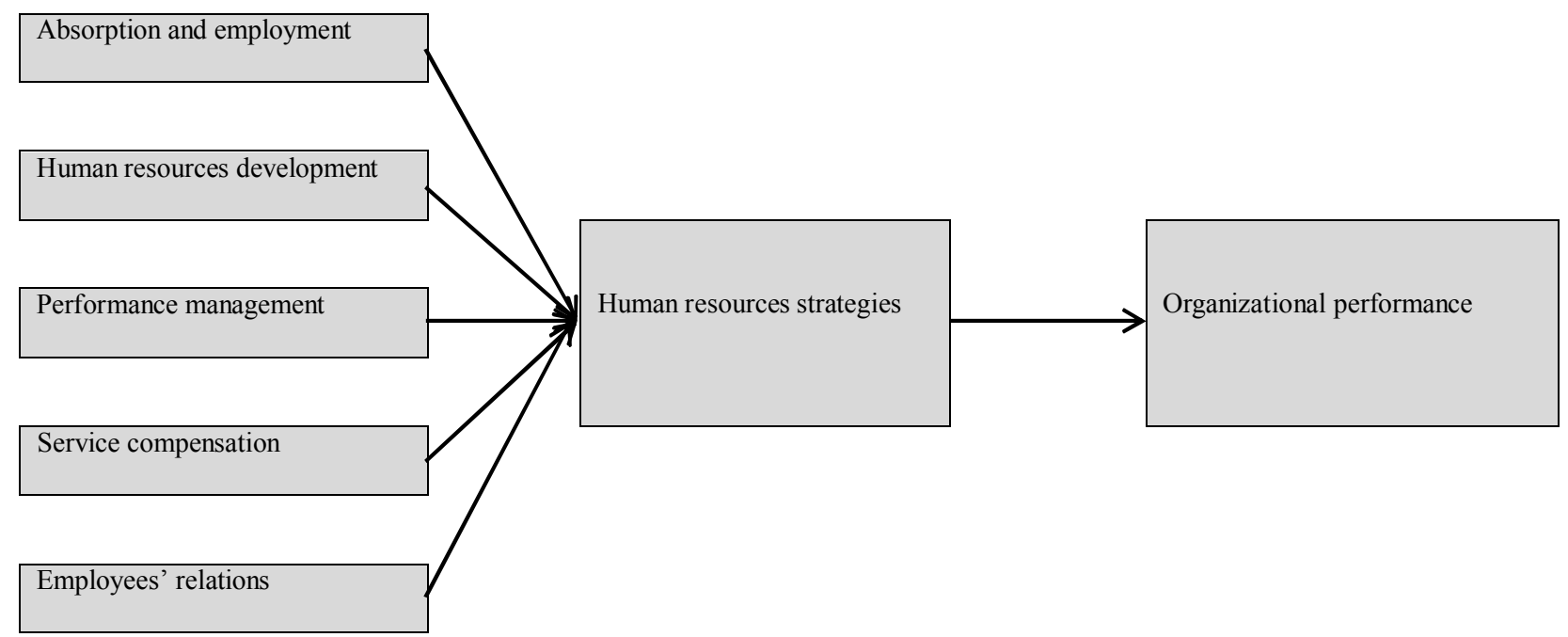

Fig. 1. The proposed study

\section{2- The literature and the history of the research}

Performance is the collective of behaviors in association with the occupation, which is manifested by individuals and the organizational performance can be considered as the result of the interaction between the three physical, financial, and human resources. It can be said that the physical and the financial resources do not create products and services on their own and this can only occur when the human element is introduced to the organization. Understanding the human behavior can increase efficiency and improve organizational performance (Abtahi \& Mousavi, 2009). Most of the previous literature on organizational performance was based on financial performance. Even though financial indexes do not correlate with the long term strategic goals of a business and cannot create an advantage under tight competitive conditions ( Wu \& Liu, 2010). During the past few years, there have been various studies conducted on issues associated with the human resources strategies and organizational performance. In this section, we review some of the studies. Sarkuobeh (2013) studied the effect of human skills on the performance of the principals of the middle schools in Iran and reported that there was a significant relationship between human skills and the performance of the principals.

Atafar et al. (2011) investigated the effects of human resources strategies on organizational performance based on the aligned scores model in revenue agency of the province of Isfahan, Iran. They reported that the absorption and employment strategy influenced on the organizational performance to some degree in all four aspects of the balanced scores model. Rahman (2010) studied human resource management practices in Bangladeshi organizations for a case study of Bangladesh center for communication program. They study indicated that in different organizations, human issues such as the ability to provide services, development of skills and motivating them had great effect of 
the performance and also on their continued cooperation with the organization and their commitment to reaching the goals of the organization. Liu et al. (2007) studied different views on strategic human resources management and organizational performance. The management of an organization usually tends to improve the human resources policies in order to achieve better performance within the organization. One of the various views on reaching this goal is to employ the best performance and best cohesion (coordination) views. The main opinion is that if there is a method better than human resources policies or a number of better methods, a better organizational performance can be achieved. They stated that to expand the role of the human resources unit as a strategic unit, human resources policies should be strategic.

\section{Methodology of the strategy}

The statistical population includes managers, directors, and experts of Barij Essence Pharmaceutical Company in the winter of 2014 and the study uses random sampling technique to select 48 individuals. With regard to the aims and the hypothesis in the present study, five strategies of absorption and employment, human resources development, performance management, service compensation, and employees' relations have been studied as independent variants. In this study, dependent variants are the organizational performance. In addition, the moderating variants examined in this research are gender, age, education, field of study, and job record. The study has designed a questionnaire in Likert scale and it has two parts: The first part is associated with surveyed people's personal characteristics and the second part if associated with survey questions in Likert scale. In the first section, five questions regarding the general description of the participant such as gender, age, education, field of study, and job record are included. The second part also includes two parts as follows,

1. Human resources strategies questionnaires: In this questionnaire, five questions are designed to measure the independent variants of the study including absorption and employment strategy, human resources development strategy, performance management strategy, service compensation strategy, and employees' relations strategy.

2. Organizational performance questionnaire: Standard questionnaires are used as a guideline in designing this questionnaire. The questionnaire is used for measuring the dependent variants of the research, which is the organizational performance. With the adjustment and the amendments to these, a question are with 50 items was conducted to measure the organizational performance of the Barij Essence Pharmaceutical Company.

In order to verify the questionnaire, the content verification method 6 was used which means first the questionnaire was given to the experts, management and behavioral sciences professors such as the assistant professor and the consultant and their opinions on the questions and the evaluation of the hypotheses were collected. In order to measure the validity of the questionnaire the Cranach's Alpha was used and with regard to the primary studies and acquired coefficients of the Cornbrash's Alpha (Table 1) the validity of the questionnaire was verified.

Table 1

Cornbrash's Alpha coefficients of the questionnaire per study variants

\begin{tabular}{clc}
\hline Row & Variants & Cornbrash's Alpha coefficients \\
\hline 1 & absorption and employment strategy & 0.835 \\
2 & human resources development strategy & 0.909 \\
3 & performance management strategy & 0.842 \\
4 & service compensation strategy & 0.717 \\
5 & employees' relations strategy & 0.910 \\
6 & Organizational performance & 0.974 \\
\hline
\end{tabular}




\section{The results}

In analytic studies, more precise and sophisticated methods are used for data analysis. However, in descriptive studies, different aspects of the phenomenon are described. Yet, in both cases, the data and statistics are analyzed as needed. In this section, we will describe the general descriptions of the participants such as gender, age, education, field of study, and job record. Fig. 2 shows details of personal characteristics of the participants.

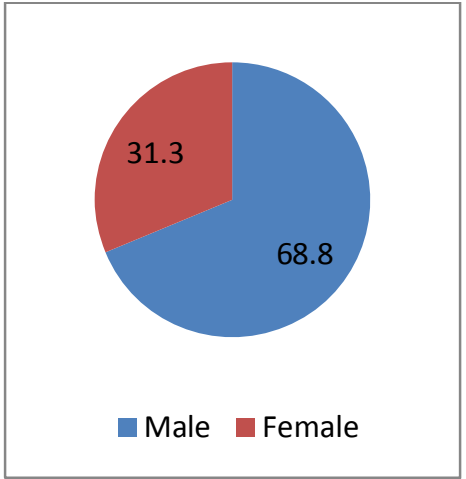

Gender

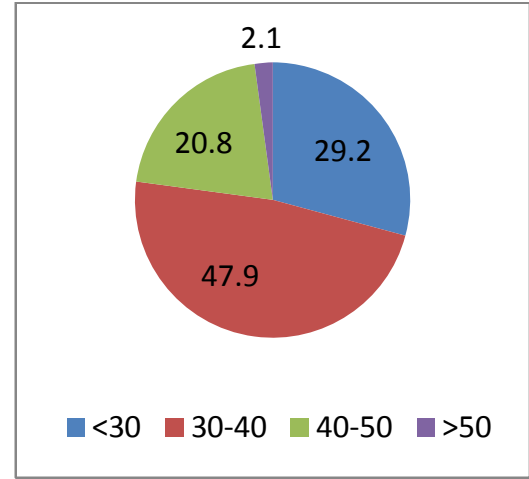

Age

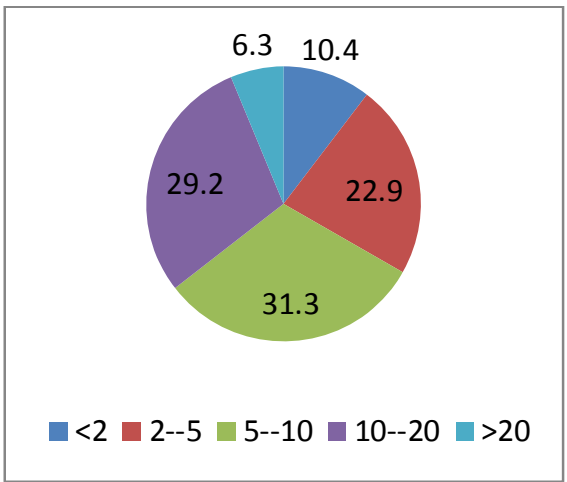

Job experience

Fig. 2. Personal characteristics of the participants

As we can observe from the results of Fig. 2, most participants were male, middle-aged people with relatively good job experiences. The implementation of Kolmogorov-Smirnov has indicated that all data were normally distributed. Table 2 demonstrates the summary of Pearson correlation test.

\section{Table 2}

The correlation coefficient related to the study's questions

\begin{tabular}{llccccc}
\hline Names of questions & Variants & $\mathrm{N}$ & Average & Std. dev. & $\mathrm{r}$ & $\mathrm{P}$ \\
\hline Dependent variant & Organizational performance & 48 & 3.088 & 0.586 & 1 & - \\
Main question & Human resources strategies & 48 & - & - & 0.881 & 0.000 \\
The first secondary question & Absorption and employment strategy & 48 & 2.645 & 0.768 & 0.722 & 0.000 \\
The second secondary question & Human resources development strategy & 48 & 2.864 & 0.721 & 0.790 & 0.000 \\
The first third question & Performance management strategy & 48 & 2.670 & 0.716 & 0.760 & 0.000 \\
The fourth secondary question & Service compensation strategy & 48 & 2.812 & 0.634 & 0.706 & 0.000 \\
The fifth secondary question & Employee relation strategy & 48 & 2.658 & 0.858 & 0.819 & 0.000 \\
\hline
\end{tabular}

With regard to Table 2 the correlation coefficients observed in were significant for all hypothesis, the statistical hypothesis $\mathrm{H}_{0}$ is dismissed and $\mathrm{H}_{1}$ is confirmed $(\mathrm{P}<0.05)$. Therefore, with $95 \%$ assurance we can confirm the study's hypothesis meaning that there was a significant relationship between human resource strategies and its components (absorption and employment strategy, human resources development strategy, performance management strategy, service compensation strategy, and employees' relations strategy) and organizational performance in Barij Essence Pharmaceutical Company.

In order to better and more logically analysis the study data and examining whether between human resource strategies and its components (absorption and employment strategy, human resources development strategy, performance management strategy, service compensation strategy, and employees' relations strategy) can forecast the organizational performance in Barij Essence Pharmaceutical Company or not, a multivariate regression was employed. The results obtained from the multivariate regression along with the multiple correlation coefficients are provided in Table 3 and Table 4. 
Table 3

Multiple correlation coefficients and the quadrate of multiple correlation of the components of human resources strategy in forecasting organizational performance

\begin{tabular}{ll}
\hline Basis variant & Organizational performance \\
\hline Model & 1 \\
Forecasting variants & Human resource strategies and its components \\
Correlation coefficients & 0.889 \\
Quadrate of multiple correlation & 0.790 \\
Moderated quadrate of multiple correlation & 0.765 \\
F coefficient & 31.573 \\
Level of significance & 0.000 \\
\hline
\end{tabular}

Based on the findings of the Table 3 it can be concluded that the human resource strategies and its components (absorption and employment strategy, human resources development strategy, performance management strategy, service compensation strategy, and employees' relations strategy), to a significant degree, influence on the organizational performance of the Barij Essence Pharmaceutical Company. These data show that the higher scores of human resources strategy result in increased level of the organizational performance of the Barij Essence Pharmaceutical Company. If the components of the human resources strategies influencing on the organizational performance of the Barij Essence Pharmaceutical Company are taken into consideration, the regression equation for the elements which are being studies can be considered in such a model:

$Y=a+\beta_{1} x_{1}+\beta_{2} x_{2}+\beta_{3} x_{3}+\beta_{4} x_{4}+\beta_{5} x_{5}$

The examination of this model based on the findings of the study is presented in Table 4.

\section{Table 4}

Regression analysis coefficient and non-standard human resources strategies and their components for forecasting organizational performance

\begin{tabular}{lccccc}
\hline Forecasting variants & Non-standard $\beta$ & Non-standard error & Standard $\beta$ & $\mathrm{t}$ & Sig. \\
\hline Constant number & 0.209 & 0.836 & - & 3.992 & 0.000 \\
Absorption and employment strategy & 0.191 & 0.083 & 0.251 & 2.296 & 0.027 \\
Human resources development strategy & 0.225 & 0.104 & 0.276 & 2.165 & 0.036 \\
Performance management strategy & -0.024 & 0.116 & -0.029 & -0.204 & 0.839 \\
Service compensation strategy & 0.225 & 0.095 & 0.244 & 2.367 & 0.023 \\
Employee relation strategy & 0.200 & 0.097 & 0.293 & 2.066 & 0.045 \\
\hline
\end{tabular}

Therefore, this coefficient replacement in the test model, the organizational performance forecast equation of organizational performance of the Barij Essence Pharmaceutical Company is obtained from the amounts of the human resources components as follows.

Organizational performance $=0.191+0.209$ (absorption and employment strategy) +0.225 (human resources development strategy) +-0.024 (performance management strategy) +0.225 (service compensation strategy) +0.200 (employees' relations strategy)

With regard to the angle of the beta coefficient (except for performance management strategy), the higher the amount of the human resources strategy components, the higher is the forecast for the organizational performance of the Barij Essence Pharmaceutical Company. 


\section{Conclusion}

In terms of examining the main question of the research, which indicates human resources strategies influence on organizational performance, we suggest the management of the company to adopt longterm strategies in the field of human resources management based on scientific research and to allocate a suitable position for human resources in companies strategic policies. Based on the finding of the research, all questions, which shows human resources strategies and its components influence on the organizational performance, we suggest the management of the company place the human resources unit in higher regard and grant them the authority to deserve in decision making and policy makings of the company. The findings from examining the first question of the research reveal that the absorption and employment strategy influences on the organizational performance. Therefore, we suggest the management set specific guidelines and procedures for hiring new personnel.

With regard to the examination of the second secondary question of the research, which shows that human resources development could influence on organizational performance, we suggest the management of the company periodically use the field observations in the company environment to determine the training requirement and adopted suitable policies and training courses to meet the real requirements of the personnel and the development of human resources.

Based on the finding from examining the third secondary question of the research, which shows that performance management strategy could influence on organizational performance we suggest the management of the company take motivational and psychological principals in employee evaluation and that the aim of the motivational programs should be the encouragement of the employees to achieve better performance and reach the organizational goals and nothing else. We also suggest that in terms of executive procedures performance management, the company should have a logical stability and avoid misplaced changes which may make some performance activates appear less important.

Based on the finding from examining the fourth secondary question of the research, which shows that service compensation strategy could influence on organizational performance we suggest issues such as the employees' life quality should be the basis for human resources strategies and current activities and non-material means and issues within the occupation should be employed to motivate the employees.

Based on the finding from examining the fifth secondary question of the research, which shows that employee relations strategy could influence on organizational performance we suggest by defining cultural guideline such as the value of interaction between the bosses and the employees the management of the company move towards an open atmosphere, supporting the creativities and innovations of the personnel etc. to create a suitable atmosphere for employee relations.

In addition, the following items are also suggested:

- Development of studies and research to better understand the human resources management and ways improving and executing it in Barij Essence Company.

- Evaluation of the performance of the Barij Essence Company with regard to the indexes of human resources and considering competitive programs to improve the performance of the company

- Creating transparency of information in human resources issues of the company to define an atmosphere suited to growth and development of human resources.

- Paying attention to the suggestions made by experts specialists, and the employees at different levels regarding human resources issues related with their activities. 


\section{References}

Abtahi, S.H., Mousavi, S.M. (2009). Development of human resources strategies (case study: Spiritual Organization). Journal of Human Resources Management Researches of Imam Hossein University, 1(3), 1-29.

Akhavan, P., \& Pezeshkan, A. (2011). Presenting the framework of developing the human sciences strategies with emphasize on dimension of knowledge. Lecturer of Human Sciences-Management Researches in Iran, 15(1), 1-29.

Allameh, S.M., \& Moghadami, M. (2010). Study the relationship between organizational learning and organizational performance, case study: Nirumoharekeh Iran khodro. Executive Management Journal, 10(1), 75-99.

Allen, R. M. \& Wright, P. M. (2006). Strategic Management and HRM. Working Paper Series, Cornell University, P 4.

Armstrong, M., \& Taylor, S. (2014). Armstrong's handbook of human resource management practice. Kogan Page Publishers.

Atafar, A., Khani Khozani, N., \& Bahrami Samani, M. (2010). Effects of human resources strategies on organizational functions based on balanced scores models in Tax Office of Isfahan Province. Management Researches, 3(9), 89-114.

Chadwick, C. (2005). The vital role of strategy in strategic human resource management education. Human Resource Management Review, 15(3), 200-213.

Javanmard, H., \& Sakhaei, F. (2009). Study the relationship between individual skills, organizational learning, innovation and organizational functions in small and mid-sized industries in Central Province. Basirat Journal, 16(44), 81-96

Liu, Y., Combs, J. G., Ketchen Jr, D. J., \& Ireland, R. D. (2007). The value of human resource management for organizational performance. Business horizons, 50(6), 503-511.

Mazloumi, N., Haghighi Kaffash, M., \& Khosravi, M. (2012). Introduction to the strategies of insurance companies and their relationship with organizational functions of those companies. Insurance Research Journal, 27(1), 1-24.

Obzeri, M., Ranjbarian, B., Fathi, S., \& Ghorbani, H. (2009). Effects of internal marketing on marketwise and organizational function in hotel industry. Perspective of Management, 31, 25-42.

Rahman, K. (2010). Human resource management practices in Bangladeshi organizations: A case study on Bangladesh centre for communication program. Available at SSRN 1570703.

Sadeghi, Z., \& Mohtashami, R. (2011). Relationship between the strategic operations of human resources and organizational innovation in a military base. Journal of Military Medicine, 13(2), 97-102.

Samei, H. (2009). Functional strategies of human resources. Tadbir Journal, 204, 27-33.

Sarkuobeh, M. (2012). Effects of human skills on the performance of secondary school principals in district 3 of Qom, M.As. Thesis, Public Management, I.A.U. Naragh, Kashan Branch, 1-114.

Wu, S. I., \& Liu, S. Y. (2010). The performance measurement perspectives and causal relationship for ISO-certified companies: a case of opto-electronic industry. International Journal of Quality \& Reliability Management, 27(1), 27-47. 